\title{
Smoking signature as a biomarker for immunotherapy
}

\author{
Mengqian $\mathrm{Li}^{1}$, Lin-Yong Zhao ${ }^{1,2}$ \\ ${ }^{1}$ State Key Laboratory of Biotherapy and Cancer Center, West China Hospital, Sichuan University, and Collaborative Innovation Center for \\ Biotherapy, Chengdu, China; ${ }^{2}$ Department of Gastrointestinal Surgery and Laboratory of Gastric Cancer, West China Hospital, Sichuan University, \\ Chengdu, China \\ Correspondence to: Mengqian Li; Lin-Yong Zhao. West China Campus, Sichuan University, \#17, Third Section, South Renmin Road, Chengdu \\ 610041, China. Email: limengqian@scu.edu.cn; 153795352@scu.edu.cn. \\ Comment on: Yang H, Ma W, Sun B, et al. Smoking signature is superior to programmed death-ligand 1 expression in predicting pathological response \\ to neoadjuvant immunotherapy in lung cancer patients. Transl Lung Cancer Res 2021;10:3807-22.
}

Submitted Dec 06, 2021. Accepted for publication Jan 14, 2022.

doi: $10.21037 /$ tlcr-21-966

View this article at: https://dx.doi.org/10.21037/tlcr-21-966

A recent study by Yang et al. reported that the smoking signature displayed a better performance than programmed death-ligand 1 (PD-L1) expression in predicting the pathological response in patients with non-small cell lung cancer (NSCLC). Based on the authors' conjecture, this possibly resulted from increased tumor mutational burden (TMB) and/or microsatellite instability (MSI) relating to smoking exposure (1). Because TMB and MSI data were unavailable in this study, we could only refer to previous studies to fully understand this speculation, during which we found that some points in the study are open to debate.

First and foremost, correlation between smoking signature and pathological response to immune checkpoint inhibitor (ICI) therapy are more likely to be mediated by TMB rather than MSI, since MSI that is often found in metastatic colorectal cancer is rarely seen in $\operatorname{NSCLC~}(2,3)$. For patients with NSCLC, mediation analysis suggested that the effect of smoking information on clinical outcomes of ICI therapy was largely mediated by the increased TMB (4). TMB has been shown to be an independent predictor ICI response (4). Therefore, we suggest that this conjecture ought to be treated with caution.

Further, a dose-response relationship between smoking history and TMB has been illuminated in patients with NSCLC $(5,6)$. Although TMB data is unavailable in the study in discussion, patients with the same smoking status as "heavy smoking" of this study showed a TMB of $\geq 10$ mutations per megabase (mut/Mb) $(5,6)$. Notably, in patients with advanced NSCLC, first-line treatment with nivolumab plus ipilimumab was associated with longer progression-free survival than chemotherapy for patients with a TMB of $\geq 10$ mut/Mb, irrespective of $\mathrm{PD}-\mathrm{L} 1$ status (7); NSCLC patients with a TMB of $\geq 12.3 \mathrm{mut} / \mathrm{Mb}$ may well have an overall survival benefit from ICI therapy (8). These studies possibly explain why heavy smoking status could better predict the benefit of immunotherapy in NSCLC patients, which, unfortunately, was not elaborate on by the authors.

To sum up, the incomplete information of TMB and MSI fails to support the authors' conjecture. Since the evaluation of smoking status is not always accurate because of biases (such as recall bias and reporting bias), we suggest focusing attention on uncovering and verifying the correlation between TMB and ICI therapy in NSCLC.

\section{Acknowledgments}

Funding: None.

\section{Footnote}

Provenance and Peer Review: This article was a standard submission to the journal. The article did not undergo external peer review.

Conflicts of Interest: Both authors have completed the ICMJE uniform disclosure form (available at https://tlcr.amegroups. com/article/view/10.21037/tlcr-21-966/coif). The authors 
have no conflicts of interest to declare.

Ethical Statement: The authors are accountable for all aspects of the work in ensuring that questions related to the accuracy or integrity of any part of the work are appropriately investigated and resolved.

Open Access Statement: This is an Open Access article distributed in accordance with the Creative Commons Attribution-NonCommercial-NoDerivs 4.0 International License (CC BY-NC-ND 4.0), which permits the noncommercial replication and distribution of the article with the strict proviso that no changes or edits are made and the original work is properly cited (including links to both the formal publication through the relevant DOI and the license). See: https://creativecommons.org/licenses/by-nc-nd/4.0/.

\section{References}

1. Yang $\mathrm{H}, \mathrm{Ma} W$, Sun $\mathrm{B}$, et al. Smoking signature is superior to programmed death-ligand 1 expression in predicting pathological response to neoadjuvant immunotherapy in lung cancer patients. Transl Lung Cancer Res 2021;10:3807-22.

2. Goodman AM, Sokol ES, Frampton GM, et al. Microsatellite-Stable Tumors with High Mutational

Cite this article as: $\mathrm{Li} \mathrm{M,} \mathrm{Zhao} \mathrm{LY.} \mathrm{Smoking} \mathrm{signature} \mathrm{as}$ a biomarker for immunotherapy. Transl Lung Cancer Res 2022;11(1):122-123. doi: 10.21037/tlcr-21-966
Burden Benefit from Immunotherapy. Cancer Immunol Res 2019;7:1570-3.

3. Luchini C, Bibeau F, Ligtenberg MJL, et al. ESMO recommendations on microsatellite instability testing for immunotherapy in cancer, and its relationship with PD-1/PD-L1 expression and tumour mutational burden: a systematic review-based approach. Ann Oncol 2019;30:1232-43.

4. Schoenfeld AJ, Rizvi H, Bandlamudi C, et al. Clinical and molecular correlates of PD-L1 expression in patients with lung adenocarcinomas. Ann Oncol 2020;31:599-608.

5. Wang X, Ricciuti B, Nguyen T, et al. Association between Smoking History and Tumor Mutation Burden in Advanced Non-Small Cell Lung Cancer. Cancer Res 2021;81:2566-73.

6. Wang X, Ricciuti B, Alessi JV, et al. Smoking History as a Potential Predictor of Immune Checkpoint Inhibitor Efficacy in Metastatic Non-Small Cell Lung Cancer. J Natl Cancer Inst 2021;113:1761-9.

7. Hellmann MD, Ciuleanu TE, Pluzanski A, et al. Nivolumab plus Ipilimumab in Lung Cancer with a High Tumor Mutational Burden. N Engl J Med 2018;378:2093-104.

8. Samstein RM, Lee CH, Shoushtari AN, et al. Tumor mutational load predicts survival after immunotherapy across multiple cancer types. Nat Genet 2019;51:202-6. 